\title{
Outcome of childhood status epilepticus and lengthy febrile convulsions: findings of national cohort study
}

\author{
C M Verity, E M Ross, Jean Golding
}

\section{Abstract}

Objective-To study outcome after lengthy febrile convulsions and status epilepticus in children.

Design-Population based birth cohort study.

Setting-The child health and education study (16004 neonatal survivors born in one week in April 1970).

Subjects-Information available for 14676 children.

Outcome measures-Clinical information and tests of intellectual performance at five and 10 years after birth.

Results-19 children had lengthy febrile convulsions and 18 had status epilepticus. Two children with status epilepticus died (one at 5 years old); neither death was directly due to the status epilepticus. Four of the $19(21 \%)$ developed afebrile seizures after lengthy febrile convulsions compared with 14 of the $17(82 \%)$ survivors after status epilepticus. Measures of intellectual performance were available for 33 of the 35 survivors: 23 were normal and 10 were not normal but eight of them had preceding developmental delay or neurological abnormality.

Conclusion-The outcome in children after lengthy febrile convulsions and status epilepticus is better than reported from studies of selected groups and seems determined more by the underlying cause than by the seizures themselves.

\section{Introduction}

According to a recent review, "convulsive status epilepticus is a medical emergency; prompt and appropriate treatment is essential to prevent brain damage and possible death." Aicardi and Chevrie wrote that "the prognosis of children's status epilepticus is grave, mental or neurological residua or both being present in at least $57 \%$ of our patients." In contrast papers by Maytal $e t a l^{3}$ and Maytal and Shinnar reported low morbidity and mortality in status epilepticus and prolonged febrile convulsions in children, prompting the article "Status epilepticus: it's not what we've taught or thought."

Why are there such differences? Hauser wrote that results from hospital based series and tertiary clinics provided biased information and that there were no population based studies of status epilepticus. ${ }^{6}$

The child health and education study is a population based study that has already provided information about febrile convulsions and epilepsy in children. ${ }^{7-10}$ We now report on the outcome in children in the study who had status epilepticus or lengthy febrile convulsions.

\section{Subjects and methods}

The child health and education study started as the 1970 British births survey, ${ }^{11}$ which enrolled 16004 neonatal survivors, $98.5 \%$ of the infants born in the
Measures of intellectual performance used to assess outcome at 5 and 10 years in children who had convulsions and status epilepticus

Assessment at 5 years
English picture vocabulary test
Copying design score
Assessment at 10 years
British ability scales:
Word definition
Recall of digits
Similarities
Matrices
Total score
Standardised mathematics test
Standardised reading test

United Kingdom in one week in April 1970. A total of $13135(82 \%)$ were assessed at 5 years of age and 14902 (93\%) at 10 years. At the assessments parents were asked: "Has the child ever had any form of convulsion, fit, seizure, or other turn in which consciousness was lost or any part of the body made an abnormal movement?" After the 10 year follow up replies were available for 14676 children, 1318 of whom had a "suspicious event." These events were validated at five and 10 years by a questionnaire to general practitioners ( $92 \%$ returned) and by obtaining hospital records for $89 \%$ of those admitted. Hospital records of those who died after the neonatal period were also studied.

By 10 years of age 84 children had suffered one or more afebrile seizures and 398 one or more febrile convulsions. ${ }^{7-10}$ Suspected seizures in the neonatal period were not included. Classification of afebrile seizures was based on the proposals of the International League Against Epilepsy. ${ }^{12}$

Having identified the children who had suffered with one or more episodes of status epilepticus or with febrile convulsions lasting more than 30 minutes we used the clinical information from the questionnaires and hospital notes together with assessments performed at 5 and 10 years of age (box) to study outcome. Children who were in special schools because of disabilities did not undergo the formal tests.

\section{DEFINTTIONS}

Epilepsy-Recurrent (more than one) afebrile seizures.

Status epilepticus-An afebrile seizure lasting more than 30 minutes or recurrent seizures lasting in total more than $\mathbf{3 0}$ minutes without return to consciousness.

Febrile convulsion or seizure-An event in infancy or childhood associated with fever but without evidence of intracranial infection or defined cause. Children with a history of afebrile seizures were excluded.

Lengthy febrile convulsions-Those lasting longer
Dr Verity.

BMF 1993;307:225-8 
than 30 minutes. Children diagnosed as having encephalitis were not included. "Prolonged" febrile convulsions were those lasting more than 15 minutes. ${ }^{7-9}$

Remission of seizures-Two or more years free of seizures before the 10 year follow up, whether or not anticonvulsants were still prescribed.

Symptomatic seizures-Those for which there was an underlying diagnosis or history of neurological insult that could be considered a predisposing cause.

\section{Results}

INCIDENCE

Nineteen $(4 \cdot 8 \%)$ of the 398 children with febrile convulsions had lengthy febrile convulsions. Eighteen $(21 \%)$ of the 84 children with afebrile seizures had one or more episodes of status epilepticus.

\section{CLINICAL DETAILS}

Full information is given in table I. The children with febrile convulsions tended to have the attacks at a younger age than those with status epilepticus (median age 11 months $v 2$ years 6 months). In a higher proportion of the children with febrile convulsions the episode of status was the first episode of seizures (17 $(89 \%) v 12(67 \%))$.

By definition there was no immediate underlying cause in any of the febrile group. One child, however, had a predisposing cause-cerebral palsy (spastic diplegia). Another child in the febrile group had a cold for 23 days and then started to convulse. His parents put him in a hot bath in the mistaken belief that this was the correct management. The right sided convulsion lasted four hours and on admission to hospital he had a temperature (presumed axillary) of $41 \cdot 7^{\circ} \mathrm{C}$. Right sided weakness persisted for several weeks and subsequently he was left handed (handedness not recorded before the attack). This was the only child in whom permanent new neurological signs were documented after a lengthy febrile convulsion.

In the status epilepticus group eight of $18(44 \%)$ were symptomatic. The diagnoses are given in table $I$. In three children the underlying cause was diagnosed by the physician managing the case as encephalitis, the clinical picture being that of a prolonged febrile illness complicated by seizures and disturbance of consciousness. There was no virological or histological confirmation of encephalitis. After the episodes of encephalitis the three children were left with physical disability (hemiplegia in one and quadriplegia in two). There were no other instances when permanent new neurological signs were documented after status epilepticus.

Most children had either tonic-clonic status or generalised status with focal features. Six had complex partial status and one had prolonged atypical absence attacks; in these children it was particularly difficult to

TABLE I-Clinical details of children with lengthy febrile convulsions and status epilepticus

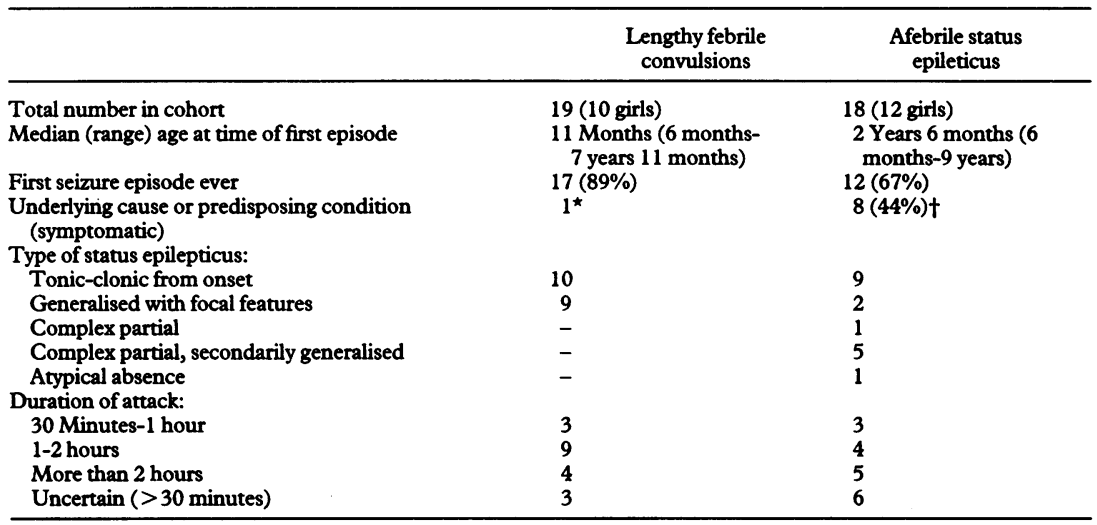

*Child with spastic diplegia.

tThree children with encephalitis; single cases of haemangio-endothelioma of cerebellum, hydrocephalus requiring ventricular shunt, severe head injury with skull fracture, head injury (probably non-accidental), Rett syndrome. judge the exact duration of the attacks. We did not include children unless there was evidence that the seizure itself (excluding the ensuing coma) lasted for at least 30 minutes.

Emergency management-Seventeen of the 19 children in the febrile convulsion group were admitted to hospital as an immediate result of the attack compared with 12 of the 18 with afebrile status epilepticus. In the afebrile group seven of the nine with tonic-clonic status and both children who had generalised status with focal features were admitted. Hospital records indicated that emergency treatment was appropriate, but we were not able formally to evaluate this.

\section{OUTCOME}

Full details are given in tables II and III.

TABLE II-Clinical details of outcome after lengthy febrile convusions and status epilepticus

\begin{tabular}{lcc}
\hline & $\begin{array}{c}\text { Lengthy } \\
\text { febrile } \\
\text { convulsions }\end{array}$ & $\begin{array}{c}\text { Afebrile } \\
\text { status } \\
\text { epilepticus }\end{array}$ \\
\hline Total number in cohort & 19 & 18 \\
Deaths & 0 & $2^{\star}$ \\
Subsequent prolonged episode of status & 0 & $8 / 17(47 \%)$ \\
Subsequent afebrile seizures & $4(21 \%)$ & $14(82 \%) \dagger$ \\
Remission & $16(84 \%)$ & $4(23 \%) \dagger$ \\
\hline
\end{tabular}

*One death immediately in child with haemorrhage from cerebellar haemangio-endothelioma, one death five years after episode of status (see text). + Significant difference between groups, $p<0.005$

TABLE II-Intellectual outcome after lengthy febrile convulsions and status epilepticus based mainly on assessments at 10 years

\begin{tabular}{|c|c|}
\hline Detail & No of children \\
\hline \multicolumn{2}{|r|}{ Lengthy febrile convulsions ( $n=19$ ) } \\
\hline $\begin{array}{l}\text { Normal } \\
\text { Not available } \\
\text { Below normal } \\
\text { Special schools }\end{array}$ & $\begin{array}{l}12 \\
4 \text { (3 Normal at } 5 \text { years) } \\
1 \text { (Hot bath, } 4 \text { hour convulsion) } \\
2 \text { (Preceding developmental delay }{ }^{\star} \text { ) }\end{array}$ \\
\hline \multicolumn{2}{|r|}{ Status epilepticus $(n=18)$} \\
\hline $\begin{array}{l}\text { Normal } \\
\text { Not available } \\
\text { Below normal }\end{array}$ & $\begin{array}{l}7 \\
2 \text { (1 Normal at } 5 \text { years) } \\
1 \text { (Hydrocephalus, shunt) } \\
1 \text { (Head injury) }\end{array}$ \\
\hline Special schools & $\begin{array}{l}5 \text { (2 Previous encephalitis, } 1 \text { Rett syndrome, } 1 \text { preceding } \\
\text { developmental delay, }{ }^{1} \text { ? (possible birth asphyxia)) }\end{array}$ \\
\hline Deaths & $\begin{array}{l}1 \text { (Encephalitis) } \\
1 \text { (Cerebellar vascular malformation) }\end{array}$ \\
\hline
\end{tabular}

Details given in table IV

\section{Lengthy febrile convulsions}

There were no deaths and no further lengthy episodes. There was a lower rate of subsequent afebrile seizures than in the status group (4/19 (21\%) $v 14 / 17$ $\left.(82 \%) ; \chi^{2} 11 \cdot 15 ; \mathrm{p}<0.005\right)$. More were in remission than were the survivors in the status group (16/19 $\left.(84 \%) v 4 / 17(23 \%) ; \chi^{2} 11.04 ; p<0.005\right)$.

The four children with lengthy febrile convulsions developed the following afebrile seizures: single tonicclonic seizure in one; single complex partial seizure in one; and recurrent complex partial seizures in two (both presented in the first year with lengthy febrile convulsions predominantly affecting one side).

Children who had lengthy febrile convulsions had a much greater risk of developing afebrile seizures than children in the cohort who had febrile convulsions lasting less than 30 minutes $(4 / 19(21 \%) v 13 / 379$ $\left.(3.4 \%) ; x^{2} 9.77 ; \mathrm{p}<0.005\right)$.

Intellectual outcome was based when possible on the assessments at 10 years (see table III). In the febrile group of 19 children the outcome measures were normal in 12 at 10 years, three at 5 years, and were not available in one. One was below normal on the 10 year tests-this was the boy with the four hour convulsion who had been placed in a hot bath. Two were in special schools; they were developmentally delayed before the episode of status (table IV). 
TABLE IV-Children in special schools at 10 years of age. Details of those with evidence of developmental delay before first lengthy febrile convulsions or episode of status epilepticus

\begin{tabular}{lll}
\hline & $\begin{array}{c}\text { Age at first lengthy } \\
\text { attack or episode of } \\
\text { status epilepticus }\end{array}$ & \multicolumn{1}{c}{$\begin{array}{c}\text { Details of } \\
\text { developmental delay }\end{array}$} \\
\hline $\begin{array}{l}\text { Febrile } \\
\text { convulsions }\end{array}$ & 3 Years 1 month & $\begin{array}{l}\text { Birth: irritable } \\
\text { 9 Months: not sitting } \\
\text { 2Years 8 months: first walked } \\
\text { Birth: "brain damage" } \\
\text { Diagnosis: spastic diplegia before } \\
\text { first lengthy attack }\end{array}$ \\
$\begin{array}{c}\text { Status } \\
\text { epilepticus }\end{array}$ & 2 Years 4 months & $\begin{array}{l}\text { 11 Months: not crawling } \\
\text { 1 Year 11 months: Griffiths's } \\
\text { developmental quotient: 59 }\end{array}$ \\
\hline
\end{tabular}

\section{Status epilepticus}

Two children died. One was admitted in status epilepticus at 10 months of age and quickly died as a result of haemorrhage from a haemangio-endothelioma of the cerebellum. The other was admitted at 7 months of age with a prolonged febrile illness associated with seizures, which was diagnosed as encephalitis and which was followed by severe mental and physical handicap. The child died age 5 years of bronchopneumonia. We did not think that either death was due to status epilepticus.

Excluding the early death, there were further episodes of status in eight of $17(47 \%)$. Of the 16 who survived until follow up, seven were normal on the tests of intellectual function at 10 years. Outcome measures were not available for two children at 10 years but one of them was normal when tested at 5 years (after the episode of status). The seven remaining children were either in special schools or were below normal on testing at 10 years: five of them had underlying neurological problems (see table III). One had delayed development before the episode of status epilepticus (see table IV). In the last child the seizure occurred at 15 months of age and, although delayed development was not documented, a reply on the parental questionnaire expressed concern about birth asphyxia, perhaps suggesting that early development was not normal.

In summary, there was information about intellectual outcome for 33 of the 37 children (two deaths, two not available). Twenty three were normal on testing at either 5 or 10 years. Ten were abnormal on testing at 10 years or were in special schools; in eight of these the attacks were symptomatic of an underlying neurological abnormality or the children were known to be developmentally delayed before the first attack. In one of the two remaining there may have been damage by hyperthermia after inappropriate management and in the other the possibility of birth asphyxia had been raised.

\section{Discussion}

We report better outcome than in many previous studies and we think that this is primarily because of the population based nature of the study.

Differences in outcome between studies are also partly explained by differences in the definitions used. Sometimes the term status epilepticus has been used for seizures lasting an hour or more. ${ }^{213}$ We chose 30 minutes or more, in common with recent studies. ${ }^{314} \mathrm{By}$ our definition febrile convulsions were "without evidence of intracranial infection or defined cause." Others have defined a febrile convulsion as "any convulsion occurring in association with any febrile illness"15; this would have required that we classify two of the children with encephalitis as having had lengthy febrile convulsions. These two children were severely handicapped after the febrile illnesses, which were diagnosed as encephalitis. In Aicardi and Chevrie's 1970 study children with encephalitis were classified separately from those with "cryptogenic" febrile status epilepticus, although the authors agreed that it was difficult to differentiate. ${ }^{2}$ Fowler applied the term "febrile convulsion" to attacks lasting from one to six hours that occurred in five children, four of whom remained unconscious after the attacks until they died. ${ }^{16}$ The evidence presented in this and previous papers $\mathrm{s}^{7-10}$ suggests that such catastrophic attacks are rare. Apart from the children with encephalitis and the child who became hyperthermic, probably due to mis-management of a febrile convulsion, there were no cases in this study in which permanent new neurological signs were documented after status epilepticus or lengthy febrile convulsions.

There are problems with our study-children were not objectively assessed before their febrile convulsions or afebrile seizures. Those who performed normally on standardised tests at 5 and 10 years might have done better if they had never had attacks. The children who were abnormal before the attacks might have become more abnormal as a result of them. We cannot comment on the effectiveness of the emergency treatment.

\section{OUTCOME AFTER LENGTHY FEBRILE CONVULSIONS}

Retrospective studies of patients with temporal lobe epilepsy have suggested that prolonged febrile convulsions were often the cause. ${ }^{17}{ }^{18} \mathrm{We}$ found, however, that only four children of the 398 with febrile convulsions in the cohort had lengthy febrile convulsions and then developed afebrile seizures. Only two of the four developed recurrent complex partial seizures. These were the two who had lengthy focal febrile convulsions in the first year of life. ${ }^{9}$

A good outcome after lengthy febrile convulsions was reported from a study that was close to ours in design - the American national collaborative perinatal project, which found no statistically increased risk of subsequent epilepsy in children with first febrile convulsions lasting more than half an hour ${ }^{19}$ and no reduction in the full scale intelligence quotient (IQ) compared with sibling controls in those with febrile convulsions lasting more than an hour. ${ }^{20}$

\section{OUTCOME AFTER STATUS EPILEPTICUS}

Previous papers have suggested that status epilepticus may cause brain damage and death. ${ }^{121321-24}$ There is good experimental, ${ }^{25}$ radiological, ${ }^{26}$ and pathological ${ }^{27} 28$ evidence that prolonged seizures may be associated with brain damage. We agree that prompt measures should be taken to prevent seizures becoming prolonged. Like Maytal et $a l^{3}{ }^{3}$ however, we conclude from our study that the outcome after status epilepticus seems determined by the underlying neurological problem rather than the status epilepticus itself.

Clinical implications
- Hospital based studies of children with pro-
longed fits tend to select the most severe cases
This population based birth cohort study
gives a more optimistic view of outcome
after prolonged febrile convulsions and status
epilepticus
- Measures of intellectual performance avail-
able for 33 of the survivors at 5 or 10 years of age,
or both, showed that 10 were not normal, but
eight of them had had preceding developmental
delay or neurological abnormality
- In this study the outcome seemed deter-
mined more by the underlying cause than by the
seizures themselves


The American national collaborative perinatal study, also population based, provided similar results. In that cohort there were eight children who had at least one afebrile seizure lasting more than 30 minutes and had a sibling control. The mean IQ of the children with the seizures was just 1 point lower than that of the controls. $^{29}$

We thank the midwives, health visitors, general practitioners, medical records officers, and clinicians who provided essential information and also the children and their parents. Professor Neville Butler initiated the child health and education study, which was funded by the Medical Research Council, the Department of Health and Social Security, and the Gertrude H Sergievsky Center, Columbia University, New York. We are grateful to Sanofi-Winthrop for a grant to help with data analysis.

1 Leppick IE. Status epilepticus: the next decade. Neurology 1990;40(suppl 2): 4-9.

2 Aicardi J, Chevrie J. Convulsive status epilepticus in infants and children. A study of 239 cases. Epilepsia 1970;11:187-97.

3 Maytal J, Shinnar S, Moshe SL, Alvarez LA. Low morbidity and mortality of status epilepticus in children. Pediatrics 1989;83:323-31.

4 Maytal J, Shinnar S. Febrile status epilepticus. Pediatrics 1990;86:611-6.

5 Freeman JH. Status epilepticus: it's not what we've thought or taught Pediatrics 1989;83:444-5.

6 Hauser WA. Status epilepticus: epidemiologic considerations. Neurology 1990;40 (suppl 2):9-13.

7 Verity CM, Butler NR, Golding J. Febrile convulsions in a national cohort followed up from birth. I. Prevalence and recurrence in the first five years of life. $B M Y 1985 ; 290: 1307-10$

8 Verity CM, Butler NR, Golding J. Febrile convulsions in a national cohort followed up from birth. II. Medical history and intellectual ability at 5 years of age. $B M^{7}$ 1985;290:1311-5.

9 Verity $C M$, Golding J. Risk of epilepsy after febrile convulsions: a national cohort study. BMF 1991;303:1373-6.

10 Verity CM, Ross EM, Golding J. Epilepsy in the first 10 years of life: findings of the child health and education study. BMf 1992;305:857-61.
11 Chamberlain R, Chamberlain G, Howlett B, Claireaux A. British births 1970 Vol 1. The first week of life. London: Heinemann, 1975.

12 Commission on Classification and Terminology of the International League Against Epilepsy. Proposal for revised clinical and electroencephalographic classification of epileptic seizures. Epilepsia 1981;22:489-501

13 Oxbury JM, Whitty CWM. Causes and consequences of status epilepticus in adults. A study of 86 cases. Brain 1971;94:733-44.

14 Dunn DW. Status epilepticus in children: etiology, clinical features, and outcome. I Child Neurol 1988;3:167-73.

15 Wallace SJ, Cull AM. Long-term psychological outlook for children whose first fit occurs with fever. Dev Med Child Neurol 1979;21:28-40.

16 Fowler M. Brain damage after febrile convulsions. Arch Dis Child 1957;32: 67-76.

17 Falconer MA, Serafetinides EA, Corsellis JAN. Etiology and pathogenesis of temporal lobe epilepsy. Arch Neurol 1964;10:233-48.

18 Ounsted C, Lindsay J, Richards P. Temporal lobe epilepsy: a biographical study. London: MacKeith Press, 1987. (Clinics in developmental medicine No 103.)

19 Nelson KB, Ellenberg $\mathrm{JH}$. Prognosis in children with febrile seizures. Pediatrics 1978;61:720-7.

20 Ellenberg JH, Nelson KB. Febrile seizures and later intellectual performance. Arch Neurol 1978;35:17-21.

21 Aicardi J, Chevrie J-J. Consequences of status epilepticus in infants an children. In: Delgado-Escueta AV, Wasterlain CG, Treiman DM, Porter RJ, eds. Advances in neurology. Vol 34. Status epilepticus. New York: Raven Press, 1983:115-25.

22 Anon. Non-convulsive status epilepticus. [Editorial.] Lancet 1987;i:958-9.

23 Yager JY, Cheang M, Seshia SS. Status epilepticus in children. Can $\mathcal{F}$ Neurol Sci 1988;15:402-5.

24 Phillips SA, Shanahan RJ. Etiology and mortality of status epilepticus in children. A recent update. Arch Neurol 1989;46:74-6.

25 Lothman E. The biochemical basis and pathophysiology of status epilepticus. Neurology 1990;40(suppl 2): 13-23.

26 Aicardi J, Baraton J. A pneumoencephalographic demonstration of brain atrophy following status epilepticus. Dev Med Child Neurol 1971;13:660-7.

27 Corsellis JAN, Bruton CJ. In: Delgado-Escueta AV, Wasterlain CG, Treiman DM, Porter RJ, eds. Advances in neurology. Vol 34. Status epilepticus. New York: Raven Press, 1983:129-39.

28 Soffer D, Melamed E, Assaf Y, Cotev S. Hemispheric damage in unilatera status epilepticus. Ann Neurol 1986;20:737-40.

29 Ellenberg JH, Hirtz DG, Nelson KB. Do seizures in children cause intellectua deterioration? NEngl f Med 1986; 314:1085-8.

(Accepted 13 May 1993)

\title{
Study of infection with HIV and related risk factors in young offenders' institution
}

\author{
A Graham Bird, Sheila M Gore, Sheila M Burns, John G Duggie
}

Immunology Department, Churchill Hospital, Headington, Oxford OX37 $\mathbf{L J}$

A Graham Bird, consultant immunologist

MRC Biostatistics Unit, Institute of Public Health, University Forvie Site, Cambridge CB2 2SR

Sheila M Gore, senior statistician

Regional Virus Laboratory, City Hospital, Edinburgh EH10 5SB

Sheila M Burns, consultant virologist

Group Medical Practice, The Health Centre, Grangemouth FK3 9EL John G Duggie, prison medical officer (part time)

Correspondence to: Dr Bird.
Abstract

Objectives-To estimate the prevalence of infection with HIV in young offenders in Scotland and to obtain information about related risk factors and previous tests for HIV.

Design-Voluntary anonymous study with subjects giving saliva samples for testing for HIV and completing questionnaires about risk factors.

Setting-Polmont Young Offenders' Institution near Falkirk, Scotland.

Subjects-421 of 424 available male prisoners in Polmont. The questionnaires of 17 of the prisoners were excluded because of inaccuracies.

Main outcome measures-Prevalence of infection with HIV and related risk behaviour.

Results-68 (17\%) of prisoners admitted misuse of intravenous drugs, of whom $17(25 \%)$ admitted having injected drugs while in prison. Three subjects admitted having anal intercourse while in prison. Prevalence of misuse of intravenous drugs varied geographically: $28 \%(33 / 120)$ of prisoners from Glasgow compared with $9 \%(7 / 81)$ of those from Edinburgh and Fife. A high level of heterosexual activity was reported, with $36 \%(142 / 397)$ of prisoners claiming to have had six or more female sexual partners in the year before they were imprisoned. Altogether 8\% (32/389) of prisoners had previously taken a personal test for HIV: $50 \%(9 / 18)$ of those who had started misusing intravenous drugs before $1989,18 \%(9 / 49)$ of those who started misuse later, and only $4 \%(14 / 322)$ of those who had not misused intravenous drugs. No saliva sample tested positive for antibodies to HIV, but 96 prisoners requested a confidential personal test for HIV as a result of heightened awareness generated by the study.

Conclusions-Voluntary, anonymous HIV surveys can achieve excellent compliance in prisons, and the interest generated by the study suggests that prisons may be suitable sites for providing education and drug rehabilitation for a young male population at high risk of future infection with HIV.

\section{Introduction}

In 1991 the Scottish Prison Service started a programme of serial anonymous surveillance of the prevalence of HIV and risk factors in selected establishments. The first studies were conducted by an external research team at HM Prison Saughton, Edinburgh, in August 1991 and October 1992. ${ }^{12}$ In 1992 surveillance was extended to Polmont Young Offenders' Institution, which is Scotland's largest establishment for young male offenders (aged 16-21). Prisoners in Polmont were invited to participate in a study of HIV prevalence, risk behaviours, and uptake of HIV tests by young males in the communities served by Polmont. We report these results and compare them with previously published results about Saughton's adult prisoners. ${ }^{12}$

\section{Subjects and methods}

Polmont Young Offenders' Institution, near Falkirk in Scotland's central region, serves the whole of 